\title{
USO DE Bacillus spp. NO CONTROLE DE FITOPATÓGENOS EM SEMENTES DE SOJA VARIEDADE BRS VALIOSA RR
}

\author{
Gustavo de Andrade Bezerra ${ }^{1}$; Daniella Aguiar Macedo' ${ }^{1}$; Ivaneide de Oliveira \\ Nascimento $^{2}$; Thatyane Pereira de Sousa ${ }^{3}$; Niedja Bezerra Costa ${ }^{1}$; Luís Felipe Rodrigues \\ de Aquino Sousa1. \\ ${ }^{1}$ Graduandos do curso de Engenharia Agronômica da Universidade Estadual do Maranhão \\ (UEMA). Imperatriz, Maranhão, Brasil. guandrade.b@gmail.com \\ 2 Professora, Mestre da UEMA. Imperatriz, Maranhão, Brasil \\ ${ }^{3}$ Mestranda em Agronomia da Universidade Federal Rural da Amazônia. Belém, Pará, Brasil.
}

RESUMO: O presente trabalho teve como objetivo avaliar o controle biológico de fitopatógenos da soja realizando microbiolização de sementes com Bacillus spp., $B$. polymyxa, B. cereus, $B$. pumilus e $B$. licheniformis. Para o teste de sanidade foi empregado o método do Blotter Test. Foram utilizadas sementes de soja da variedade BRS Valiosa RR. As sementes foram microbiolizadas com a suspensão de bactérias em solução salina $(\mathrm{NaCl} 0,85$ $\%$ ), na concentração de $\mathrm{OD}_{540}=0,5 \mathrm{AA}$ e levadas à mesa de agitação por 30 minutos. As sementes foram plaqueadas em papel de filtro em experimentos conduzidos em laboratório com delineamento inteiramente casualizado com seis tratamentos e cinco repetições. Os parâmetros avaliados foram incidência e redução dos patógenos em sementes de soja. Houve a avaliação de sementes sadias e infectadas. A variedade BRS valiosa RR apresentou $48 \%$ de sementes sadias e $52 \%$ de sementes infectadas. De acordo com a análise da incidência e controle de fitopatógenos em sementes de soja com uso de Bacillus spp., as espécies Bacillus licheniformis e Bacillus pumilus apresentaram os maiores índices percentuais de controle na variedade utilizada no experimento.

PALAVRAS-CHAVE: controle biológico, microbiolização, sanidade.

\section{USE OF Bacillus spp. NO CONTROL PATHOGENS IN SOYBEAN SEED VARIETY BRS VALUABLE RR}

\begin{abstract}
This study aimed to evaluate the biological control of plant pathogens of soybean seed microbiolization performing with Bacillus spp., B. polymyxa, B. cereus, B. pumilus and B. licheniformis. For the sanity test method was employed the Blotter Test. Seeds of soybean cultivar BRS Valiosa RR. The seeds were microbiolized with the bacterial suspension in saline $(0.85 \% \mathrm{NaCl})$ at a concentration of $\mathrm{OD}_{540}=0.5 \mathrm{AA}$ and brought to a shaking table for 30 minutes. Seeds were plated on filter paper in experiments conducted in the laboratory with a completely randomized design with six treatments and five replications. We evaluated the incidence and reduction of pathogens in seeds. There was the assessment of healthy and infected seeds. The BRS Valiosa RR showed $48 \%$ of healthy seeds and $52 \%$ of infected seeds. According to the analysis of the incidence and control of pathogens in seeds with the use of Bacillus spp., the species Bacillus licheniformis and Bacillus pumilus showed the highest percentage rates of control in the range used in the experiment.
\end{abstract}

KEYWORD: biological control, health, microbiolization. 
A soja (Glycine max (L.) Merril) que hoje é cultivada mundialmente, é muito diferente dos ancestrais que lhe deram origem: espécies de plantas rasteiras que se desenvolviam na costa leste da Ásia, principalmente ao longo do Rio Amarelo, na China. Sua evolução começou com o aparecimento de plantas oriundas de cruzamentos naturais, entre duas espécies de soja selvagem, que foram domesticadas e melhoradas por cientistas da antiga China (EMBRAPA, 2004).

Tendo em vista o grande número de doenças que podem afetar a cultura da soja, o emprego de medidas de controle que minimizem as perdas é fundamental. Dentre essas medidas, o uso de cultivares resistentes, sementes livres de patógenos e o tratamento químico podem garantir a obtenção de plantas mais sadias e produtivas. O tratamento de sementes é usado principalmente com a finalidade de permitir a germinação de sementes infectadas, controlar patógenos transmitidos pela semente e proteger as sementes dos fungos do solo (HENNING et al., 1994).

Diferentes tipos de microrganismos estão sendo investigados, no Brasil, onde antagonistas isolados podem inibir $\mathrm{o}$ crescimento de patógenos, em meio de cultura. $\mathrm{O}$ potencial de agentes microbianos de biocontrole, através da microbiolização das sementes, já foi registrado. Esses microrganismos atuam como indutores de resistência, provocando alterações citoquímicas durante o ataque de patógenos (KLOEPPER et al., 2004).

A microbiolização consiste na utilização de microrganismos ou de seus metabólitos na proteção de sementes, sendo este método já utilizado na promoção de germinação e crescimento e no controle de diferentes patógenos (FARIA et al., 2003). Contudo, este trabalho buscou avaliar o efeito de isolados de Bacillus spp. no controle de fitopatógenos em sementes de soja (Glycine $\max (\mathrm{L}$.$) Merril).$

O experimento foi conduzido no Laboratório de Fitopatologia, Microbiologia e Alimento e no Laboratório de Entomologia da Universidade Estadual do Maranhão - Centro de Estudos Superiores de Imperatriz (UEMA-CESI). Foram utilizadas sementes de soja da variedade BRS Valiosa RR, disponibilizada pela Embrapa Arroz e Feijão (Goiás), colhidas no ciclo 2011/2012. As sementes de soja passaram por dois procedimentos antes da análise: o primeiro o teste de sanidade de sementes (Blotter Test) e o segundo a microbiolização de sementes com Bacillus spp.

$O$ teste de sanidade consistiu na utilização de 400 sementes. As sementes de soja foram inicialmente desinfestadas 
através de imersão em uma solução de hipoclorito de sódio $(\mathrm{NaOCl})$, a $1 \%$ de cloro ativo por 3 minutos, seguida de 3 lavagens com água destilada. Em seguida, as mesmas foram plaqueadas em placas de Petri, previamente esterilizadas, contendo três camadas de papel de filtro umedecido com água destilada e esterilizada (ADE), sendo plaqueadas 20 sementes por placa segundo as regras de análise de sementes pré-estabelecidas (BRASIL, 2009). As placas foram acondicionadas em bancadas do Laboratório de Entomologia da Universidade Estadual do Maranhão Centro de Estudos Superiores de Imperatriz, por sete dias em condições de fotoperíodo, onde foi possível realizar um levantamento de patógenos nas sementes, com auxílio de microscópio e metodologia comparativa.

Para avaliar a redução da incidência dos fitopatógenos em sementes de soja, foi adotada a metodologia citada por Ludwig et al (2004) com modificações, que consiste em microbiolizar as sementes com os isolados de Bacillus, na forma de suspensão, adicionando-se solução salina ( $\mathrm{NaCl} 0,85 \%)$ a cada um dos Bacillus, sendo a concentração ajustada para $\mathrm{OD}_{540}=0,5$. As sementes foram imersas nesta suspensão e agitadas durante 30 minutos a $25{ }^{\circ} \mathrm{C}$, em recipientes contendo 100 sementes para cada isolado.
Após esse procedimento as sementes foram plaqueadas, usando-se 100 sementes/Bacillus pelo método do papel de filtro em placas de Petri (BRASIL, 2009), incubadas à $26,5^{\circ} \mathrm{C}$, sob regime de fotoperíodo de 12 horas de luz/ 12 horas de escuro. A avaliação da incidência dos patógenos ocorreu após sete dias, examinando-se individualmente as sementes em microscópio estereoscópico para observação da incidência dos fitopatógenos. O delineamento estatístico adotado foi inteiramente casualizado, com cinco isolados e cinco repetições, sendo que cada placa de Petri com 20 sementes constituiu uma unidade experimental. A testemunha constou somente das sementes imersas na solução salina. Os tratamentos ficaram da seguinte forma: T0 Testemunha; T1 - Bacillus pumilus; T2 Bacillus polymyxa; T3 - Bacillus licheniformis; T4 - Bacillus sp.; T5 Bacillus cereus.

No teste de sanidade realizado a variedade BRS Valiosa RR, apresentou $48 \%$ de sementes infectadas, para a instalação da cultura em campo é um índice baixo, dentre os fatores que pode interferir cita-se o tempo de armazenamento, condições de armazenamento e o teor de umidade das sementes (LUDWIG et al., 2004).

De acordo com a incidência fúngica, pode-se identificar as seguintes espécies 
patogênicas: Aspergillus niger, Aspergillus flavus, Aspergillus ochraceus, Fusarium semitectum, Cercospora sojina,
Trichoderma sp., Rhyzopus sp. e Penicillium sp. (Figura 1).

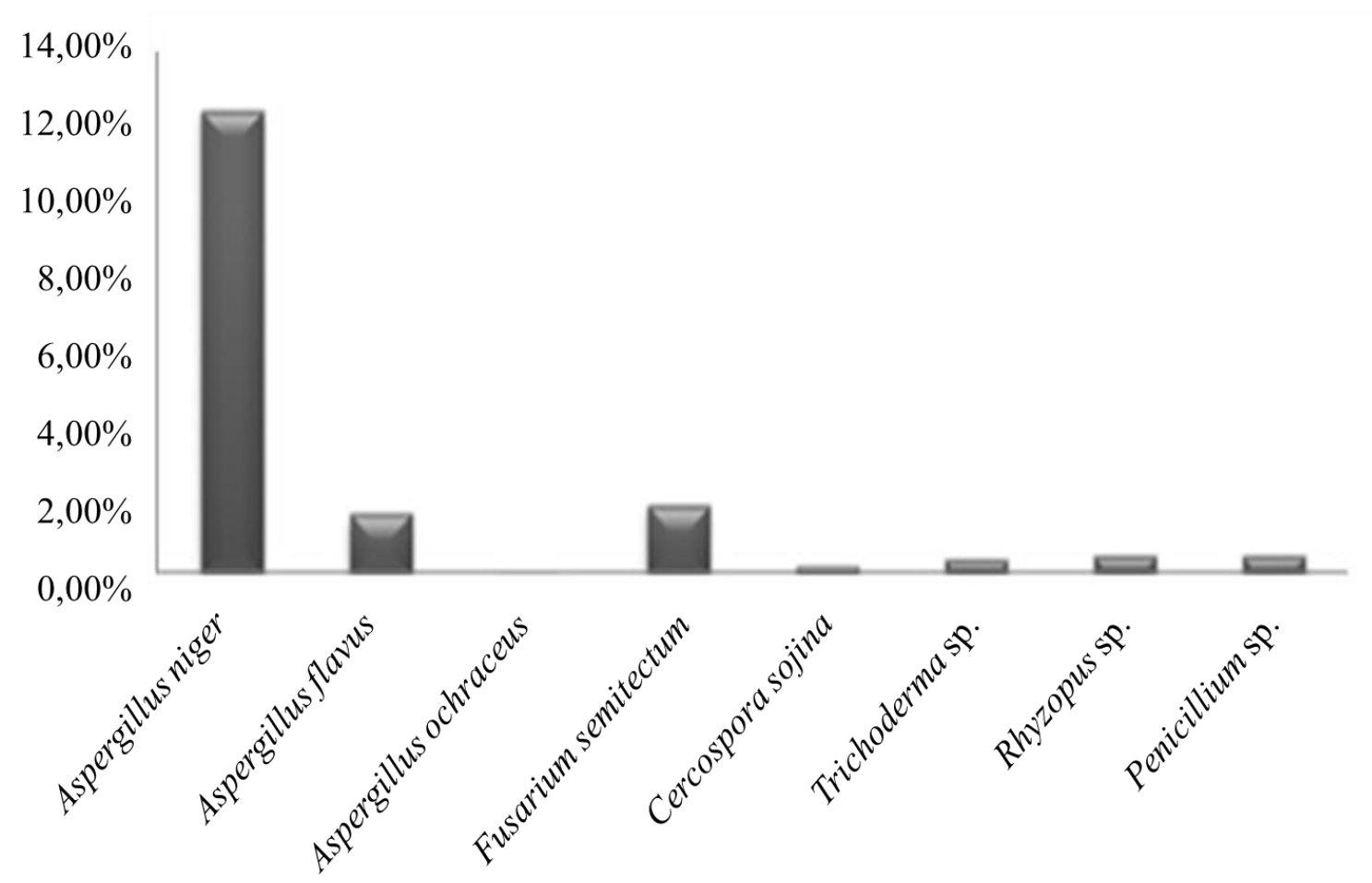

Figura 1. Incidências fúngicas na variedade de soja BRS Valiosa em teste de sanidade (Blotter Test), Imperatriz, MA, 2012.

$\mathrm{Na}$ avaliação sanitária das sementes, houve elevada incidência de patógenos de armazenamento na variedade analisada. $\mathrm{O}$ fungo Aspergillus niger foi o de maior incidência, apresentando-se com 12,50\%. Entretanto, os patógenos que transmitem doenças de campo tiveram baixa incidência. Diversos fatores podem influenciar na variação dos testes de incubação dentre os principais está à condição de armazenamento das amostras, onde o controle da temperatura e da umidade relativa do ar é indispensável para preservar a viabilidade da semente e dos patógenos (HENNING, 2005).

Observou-se eficiência nos tratamentos com espécies de Bacillus, houve diferença significativa na redução da incidência fúngica entre as sementes tratadas com Bacillus e não tratadas 
(testemunha com hipoclorito de sódio), onde as sementes não microbiolizadas apresentaram incidência fúngica de $32 \%$ em sementes da variedade BRS Valiosa RR. Entretanto, em sementes tratadas e microbiolizadas com Bacillus sp. houve uma redução considerável de colônias de gêneros fitopatogênicos em sementes. Portanto, a microbiolização de sementes de soja, nesse estudo mostrou ser um tratamento eficiente, se destacando as espécies Bacillus licheniformis e Bacillus pumilus no controle de fungos incidentes em sementes de soja de acordo com a Tabela 1, mostrando-se assim com percentuais de $99,83 \%$ e $99,22 \%$, respectivamente, de controle de fitopatógenos nesta variedade de soja. No manejo integrado de doenças, o tratamento sanitário das sementes é considerado uma das medidas mais recomendadas por controlar doenças na fase que antecede à implantação da cultura, possibilitando um menor uso de defensivos químicos, evitando problemas graves de poluição do ambiente (MACHADO, 2000).

$\mathrm{Na}$ análise sanitária das sementes, a variedade BRS Valiosa RR, apresentou baixa incidência fúngica. Contudo, nas análises de incidência e controle de fitopatógenos com o uso de Bacillus, os isolados Bacillus licheniformis e Bacillus pumilus gerou maior efeito de controle de patógenos em sementes de soja.

Tabela 1. Análise do efeito das espécies de Bacillus spp. no controle biológico de fitopatógenos em sementes de soja (Glycine max (L.) Merrill).

\begin{tabular}{lcc}
\hline & Avaliação $\left(\mathrm{n}^{\mathbf{o}}\right.$ de colônias $)$ & Percentual de controle $(\%)$ \\
\cline { 2 - 3 } Tratamento & BRS Valiosa RR & BRS Valiosa RR \\
\hline T - Testemunha & $9,22 \mathrm{bc}$ & $84,25 \%$ \\
T1 - Bacillus pumilus & $0,10 \mathrm{c}$ & $99,83 \%$ \\
T2 - Bacillus polymyxa & $12,80 \mathrm{ab}$ & $78,13 \%$ \\
T3 - Bacillus licheniformis & $0,46 \mathrm{c}$ & $99,22 \%$ \\
T4 - Bacillus sp. & $21,00 \mathrm{a}$ & $64,12 \%$ \\
T5 - Bacillus cereus & $15,40 \mathrm{ab}$ & $73,69 \%$ \\
\hline CV $(\%)$ - 40.24 \% & &
\end{tabular}

Médias seguidas de mesma letra, minúscula entre linhas e maiúsculas entre colunas, não diferem entre si pelo teste de Tukey a $5 \%$.

\section{REFERÊNCIAS}

BRASIL. Manual de Análise Sanitária

de Sementes. Ministério da Agricultura, Pecuária e Abastecimento. Secretaria de
Defesa Agropecuária.Brasília: Mapa/ACS, 2009. 200 p.

EMBRAPA, Tecnologias de Produção da Soja Região Central do Brasil 2004. 
Disponível em: <www.cnpso.embrapa.br/producaosoja/Soj anoBrasil.htm>. Acesso em 17 abr.2013.

FARIA, A. Y. K. et al. Qualidade fisiológica de sementes de algodoeiro submetidas a tratamentos químico e biológico. Revista Brasileira de Sementes, v.25, n.1, p.121-127, 2003.

HENNING, A. A. et al. Tratamento e inoculação de sementes de soja. Londrina: EMBRAPA-CNPSo, 1994. 6p.

HENNING, A. A.; ALMEIDA, A. M. R.; GODOY, C. V.; SEIXAS, C. D. S.; YORINORI, J. T.; COSTAMILAN, L. M.; FERREIRA， L. P.; MEYER, M. C.; SOARES, R. M.; DIAS, W. P. Manual de Identificação de Doenças de Soja: Londrina: Embrapa Soja, 2005. (Documentos Embrapa Soja, n. 256). p. 72. KLOEPPER, J. W. et al. Nature and application of biocontrol microbes: Bacillus spp. American Phytopathological Society, v. 94, n. 11, p.1259-1266, 2004.

LUDWIG, J.; MOURA, A. B.; SANTOS, A. S.; LORENSI, J. Incidência de Gerlachia oryzae em lotes de sementes microbiolizadas com isolados de bactérias biocontroladoras. In: SIMPÓSIO BRASILEIRO DE PATOLOGIA DE SEMENTES, 8., 2004, João Pessoa, Anais...João Pessoa, 2004. p. 184.
MACHADO, J. C. Tratamento de sementes no controle de doenças. Lavras: LAPS/ UFLA/ FAEPE, 2000. p. 138. 